\title{
Title: Convex Bone Deformity after Closed Reduction of Nasal Bone Fracture
}

Authors' full names and affiliations:

Hiroshi Nishioka ${ }^{a}$, Shoji Kondoh ${ }^{b}$, Shunsuke Yuzuriha ${ }^{a}$

${ }^{a}$ Department of Plastic and Reconstructive Surgery, Shinshu University School of

Medicine, 3-1-1 Asahi Matsumoto, Nagano 390-8621, Japan

bepartment of Plastic and Reconstructive Surgery, Ina Central Hospital, 1313-1

Koshirokubo Ina, Nagano 396-8555, Japan

Name and address for correspondence:

Hiroshi Nishioka, MD

Department of Plastic and Reconstructive Surgery

Shinshu University School of Medicine

3-1-1 Asahi Matsumoto, Nagano 390-8621, Japan

Telephone number: 011-81-263-35-4600

Facsimile number: 011-81-263-37-3024

E-mail address: hiroshi_nishioka@yahoo.co.jp 


\section{Summary}

Background: Nasal fractures are the most common type of facial fracture treated by plastic surgeons. Here, we clarify the postoperative deformities that frequently remain after closed reduction of fresh nasal bone fracture by three-dimensional computed tomography (3D-CT).

Methods: A total of 100 consecutive cases of fresh nasal bone fracture in patients treated between May 2010 and January 2016 were examined. After closed reduction, the overall appearance of the arch formed by the nasal bone and maxillary process was evaluated as "Excellent", "Good", or "Fair". Patients were also asked about their overall satisfaction with the operation, and the responses were classified as "Satisfied", "Neutral", or "Dissatisfied".

Results: Eighty-six patients underwent 3D-CT examination both at the time of the initial consultation and 3 months after the operation. The results were "Excellent" in 69 patients and "Good" in 17 patients, with none of the patients having only "Fair" results. Convex bone deformities on one side were seen in all six bilateral type fractures evaluated as "Good". All patients classified as "Excellent" reported being "Satisfied" with the results, but some patients classified as "Good" gave a "Neutral" evaluation regarding their satisfaction. 
Conclusions: The residual deformities seen in bilateral type fractures were most notable, and they were all convex bone deformities on one side. Plastic surgeons should use ultrasonography or other reliable new methods in addition to visual inspection during the operation to successfully treat the region of the convex fracture.

Key Words: nasal fracture; secondary nasal deformity; convex bone deformity; bilateral fracture type; facial bone fracture 


\section{Introduction}

Nasal fractures are the most common type of facial fracture treated by plastic surgeons ${ }^{1)}$. The operations are simple, and postoperative evaluations are seldom performed. There have been few reports regarding evaluation of secondary nasal deformities after treating fresh nasal bone fractures. In the present study, we used threedimensional computed tomography (3D-CT) to examine both the preoperative and postoperative shapes of the nasal fractures to clarify the postoperative deformities that frequently remain after closed reduction of fresh nasal bone fractures.

\section{Methods}

A total of 100 consecutive cases of fresh nasal bone fractures in patients that visited our hospital between May 2010 and January 2016 (70 males, 30 females; age range, 2-87 years) were examined. Cases were classified into four types of fracture: unilateral, bilateral, frontal and frontal/lateral mixed ${ }^{2) 3) 4}$ ) (Fig. 1). This study was performed in accordance with the "Strengthening the Reporting of Observational Studies in Epidemiology" guidelines. The study protocol was reviewed and approved by our local institutional review board.

Closed reduction was performed under general anaesthesia in all patients. 
Depressed bone fractures were manipulated outward and convex bone fractures were manipulated inward ${ }^{5)}$. Internal fixation was performed with nasal packing and external fixation was performed with a metallic splint. Internal fixation was removed 1 week after the operation, and external fixation was fitted throughout the day for 2 weeks after the operation.

The cases were classified by measuring the angle $(\theta)$ between the nasal bone and the maxillary bone on postoperative 3D-CT (Fig. 2). Angles close to $0^{\circ}$ were considered to indicate good reduction. The overall appearances of the arch formed by the nasal bone and maxillary process were also classified on a three-point scale ${ }^{4) 6}$. Angle measurement and scoring were performed by three plastic surgeons that were not involved in the operation. The average values of the angle measurement and the scoring were recorded.

A score of "Excellent" was given if the angle of the fractured portion was $<10^{\circ}$, there was no gap in the fractured portion and the arch had a smooth shape. A score of "Good" was given when there was a clear gap in the fractured portion or the shape of the arch was rough. The appearance was classified as "Fair" if the surgeon determined that reoperation was necessary. Convex bone deformity or depressed bone deformity was determined in cases in which the angle of the fractured portion was $>10^{\circ}$ (Fig. 3). 
overall satisfaction on a three-point scale: "Satisfied", "Neutral" or "Dissatisfied".

\section{Results}

3D-CT examinations were performed at the initial consultation and 3 months after the operation in 86 of 100 patients. These 86 patients wished to undergo 3D-CT to check their postoperative results regardless of satisfaction. We checked the postoperative results by visual inspection in the remaining 14 patients that were satisfied with the results and did not elect to undergo 3D-CT. The fractures consisted of bilateral type $(n=45)$, unilateral type $(n=8)$, frontal type $(n=12)$ and frontal/lateral mixed type $(n=21)$ (Fig.4). "Excellent" results were obtained in 69 patients and "Good" results were obtained in 17 patients, with none of the patients showing "Fair" results. "Good" results were found in six bilateral type fractures, no unilateral type fractures, one frontal type fracture and 10 frontal/lateral mixed type fractures (Fig. 5). Convex bone deformities on one side were seen in all six bilateral type fractures evaluated as "Good". Of the 10 frontal/lateral mixed type fractures evaluated as "Good," convex bone deformities were seen in seven cases, depressed bone deformities were seen in six cases and frontal fractured deformities were seen in two cases (Fig. 6).

Ninety-one patients reported that they were "Satisfied" with the postoperative results, nine patients were Neutral" and none of the patients were "Dissatisfied". For the 
cases classified as "Excellent" in all the types of fracture, all of the patients were "Satisfied" with the results. Some patients with "Good" evaluation reported being "Satisfied" with the results, but four patients with bilateral type fractures and five with frontal/lateral mixed type fractures classified as "Good" gave a "Neutral" evaluation (Fig. 7).

\section{Discussion}

Nasal bone fracture is the most common type of facial fracture encountered in our daily clinical consultation. Under closed reduction, it is not possible to visualise the fractured bone segment directly, and many surgeons may feel uneasy about whether adequate reduction has been achieved following treatment, which has may have consequences for postoperative external nose deformity.

There have been many reports regarding the incidence of post-reduction nasal deformities ${ }^{78) 9)}$. Watson et al. reported a secondary nasal deformity incidence rate of $29 \%$ $-50 \%{ }^{7)}$. Waldron et al. performed a prospective study of 100 patients, and reported a postreduction deformity incidence rate of $14 \%-15 \%{ }^{8)}$. In a prospective study of 756 patients, Murray et al. reported an incidence rate of $41 \%$ for post-reduction deformity ${ }^{9)}$. There have been many reports regarding the incidence of post-reduction nasal deformities, but there 
have been few detailed analyses regarding the types of nasal fracture. Many reports indicated that frontal/lateral mixed fractured type was difficult to manipulate. Motomura et al. reported a 56\% incidence of secondary nasal deformity in frontal/lateral mixed fractured type, which was much higher than the rates for other types of fracture ${ }^{6)}$.

Our results showed an incidence rate of 19\% (17 of 86 patients) for secondary nasal deformity. Although this incidence seems slightly high, we used 3D-CT to evaluate nasal deformity, which is more accurate than the methods used in previous studies. We obtained good results for the frontal fracture type compared to the other types, and deformities were mostly seen in the frontal/lateral mixed fracture type. These observations were consistent with previous reports. The residual deformities seen in bilateral type fractures were most notable, and all were unilateral convex bone deformities. Surprisingly, there were no cases of depressed bone deformity. These observations suggested that pushing down the convex bone part is probably more difficult than elevating the depressed bone part. In addition, there were more cases of convex bone deformity than depressed bone deformity in the frontal/lateral mixed fracture type.

It is important to evaluate the results postoperatively as in other types of fracture. CT is much more reliable than plain film as used previously for diagnosis and evaluation of nasal fracture ${ }^{2) 10)}$. In addition, 3D-CT provides high spatial resolution ${ }^{11)}$. Using 3D-CT, 
operations can be evaluated from another point of view and this experience can be applied in future cases ${ }^{6) 12}$. However, there may be some concerns about the risks associated with radiation exposure in repeated CT scans 3 months after surgery ${ }^{13) 14) 15)}$. There have been some reports regarding use of ultrasonography in cases of nasal fracture for intraoperative and postoperative assessment of surgical outcomes ${ }^{16) 17) 18) 19)}$. Intraoperative ultrasonography allows visualisation of local and superficial fractures of the nasal bone and it may be useful for manipulating convex bone fractures, which is much more difficult than manipulating regions of depressed bone. Surgeons should not depend on ultrasonography alone, but it should be used in addition to visual inspection during the operation. 3D-CT 3 months after surgery is necessary especially in patients requiring reoperation. However, for patients that are satisfied with the results, ultrasonography may be used as an alternative to evaluate the postoperative results.

The evaluation of postoperative results on 3D-CT corresponds to patient satisfaction. All of the patients evaluated as "Excellent" for all types of fracture were satisfied with the results, but some patients classified as "Good" gave a "Neutral" evaluation; these latter patients all complained about the residual convex bone deformity, which they could feel from the surface of the skin. Although we explained the possibility of reoperation by osteotomy to treat the convex bone part, all of these patients refused to 
undergo another operation. Thus, surgeons should treat the nasal fracture in the first single operation by closed reduction.

\section{Conclusions}

The results presented here indicated that it is possible to treat frontal fracture type, most cases of uncomplicated frontal/lateral mixed fracture type, and the depressed fractured part of the bilateral/unilateral fractured type by closed reduction. It is difficult to manipulate the convex fractured part. Most patients were satisfied with the operation results, but some complained about the convex bone deformity. Plastic surgeons should use ultrasonography or other reliable new methods in addition to visual inspection during the operation to successfully treat the convex fractured part in the first single operation by closed reduction.

\section{References}

1) Kucik CJ, Clenny T, Phelan J. Management of acute nasal fractures. Am Fam Physician 2004;70:1315-20

2) Paul NM, Bernard M, Stuart M, et al. Toward CT-based facial treatment. Plast

Reconstr Surg 1990; 85:202-212 
3) Stranc MF, Robertson GA, Phil M. A classification of injuries of the nasal skeleton. Ann Plast Surg 1979;2:468-474

4) Shimada K, Kamei K. Evaluation of K-wire fixation for nasal bone fractures using CT scans. J Jpn Plast Reconstr Surg 1996;16:314-319

5) Rohrich RJ, Adams WP. Nasal fracture management: Minimizing secondary nasal deformities. Plast Reconstr Surg 2000;106:266-273

6) Motomura $\mathrm{H}$, Muraoka M, Yabe T, et al. Changes in fresh nasal bone fractures with time on computed tomographic scans. Ann Plast Surg 2001;47:620-624

7) Watson DJ, Parker AJ, Slack RW, et al. Local versus general anesthetic in the management of the fractured nose. Clin Otolaryngol 1988;13:491

8) Waldron J, Mitchell DB, Ford G. Reduction of fractured nasal bones: Local versus general anesthesia. Clin. Otolaryngol 1989;14:357

9) Murray JAM, Maran AGD. The treatment of nasal injuries by manipulation. J Laryngol Otol 1980;94:1405

10) Hwang K, You SH, Kim SG, et al. Analysis of nasal bone fractures; a six-year study of 503 patients. J Craniofac Surg 2006 Mar;17(2):261-4

11) Yoshikawa T, Miyajima A, Fujita Y, et al. Analysis of fracture patterns in unilateral type lateral nasal fractures using three-dimensional CT images. JPN J Plast 
Reconst Surg 2013;56:1189-1195

12) Yabe T, Motomura H, Muraoka M. Post-operative evaluation of nasal bone fractures using CT scans and the necessity for this. JPN J Plast Reconst Surg $1999 ; 42: 303-307$

13) Berrington de González A, Darby S. Risk of cancer from diagnostic X-rays: estimates for the UK and 14 other countries. Lancet. 2004;363:345-351

14) Pearce MS, Salotti JA, Little MP, et al. Radiation exposure from CT scans in childhood and subsequent risk of leukaemia and brain tumours: a retrospective cohort study. Lancet. 2012;380:499-505

15) Mathews JD, Forsythe AV, Brady Z, et al. Cancer risk in 680,000 people exposed to computed tomography scans in childhood or adolescence: data linkage study of 11 million Australians. BMJ. 2013;346:f2360

16) Hirai T, Manders EK, Nagamoto K, et al. Ultrasonic observation of facial bone fractures: report of cases. J Oral Maxillofac Surg. 1996;54:776-779

17) Park $\mathrm{CH}$, Joung $\mathrm{HH}$, Lee $\mathrm{JH}$, et al. Usefulness of ultrasonography in the treatment of nasal bone fractures. J Trauma. 2009;67:1323-1326.

18) Kim DH, Kim KS. Usefulness of ultrasonography-assisted closed reduction for nasal fracture under local anesthesia. Arch Craniofac Surg. 2015;16:151-153 
19) Yabe $T$, Tsuda $T$, Hirose $S$, et al. Comparison of ultrasonography-assisted closed reduction with conventional closed reduction for the treatment of acute nasal fractures. J Plast Reconstr Aesthet Sug. 2014;67:1387-1392 


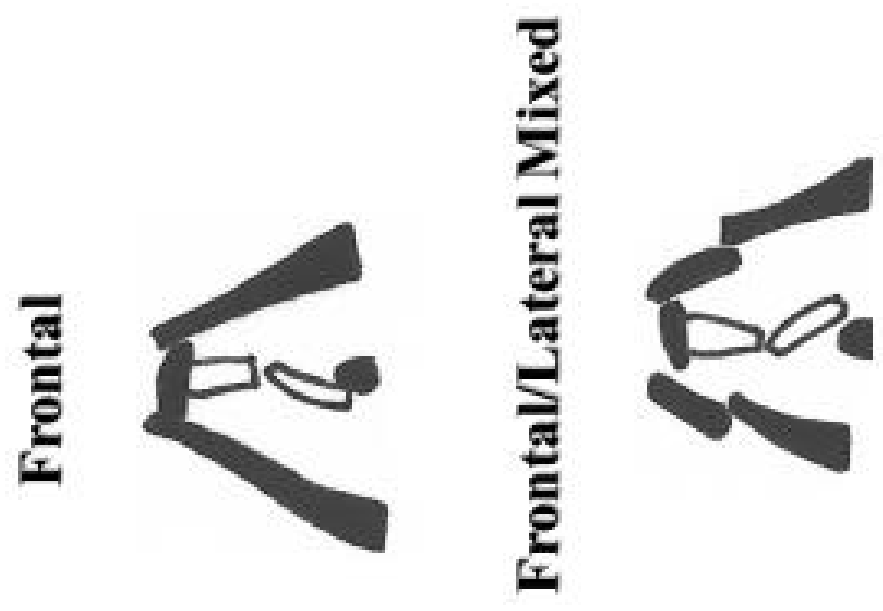

葛
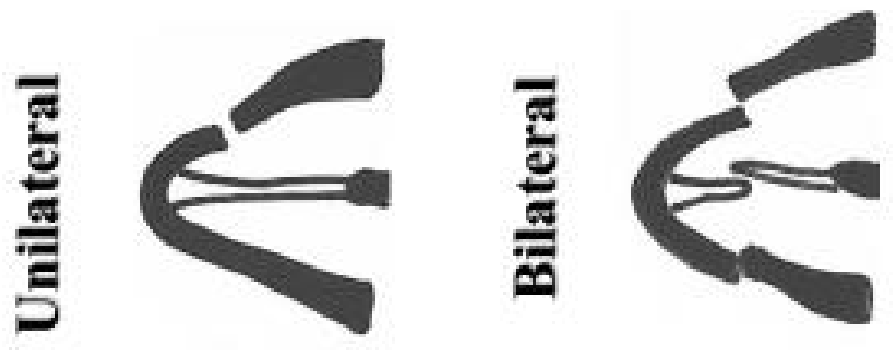

ह 


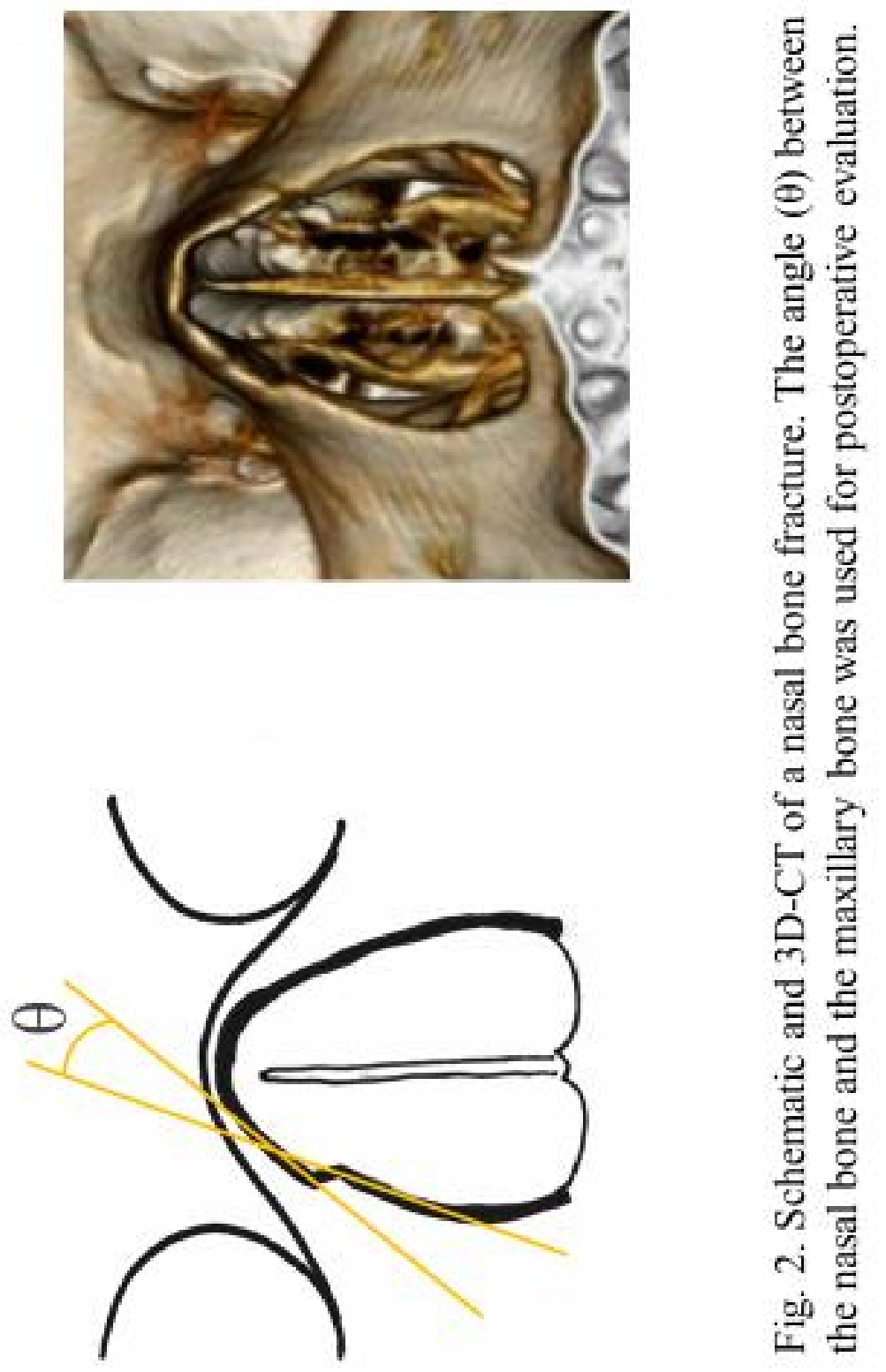




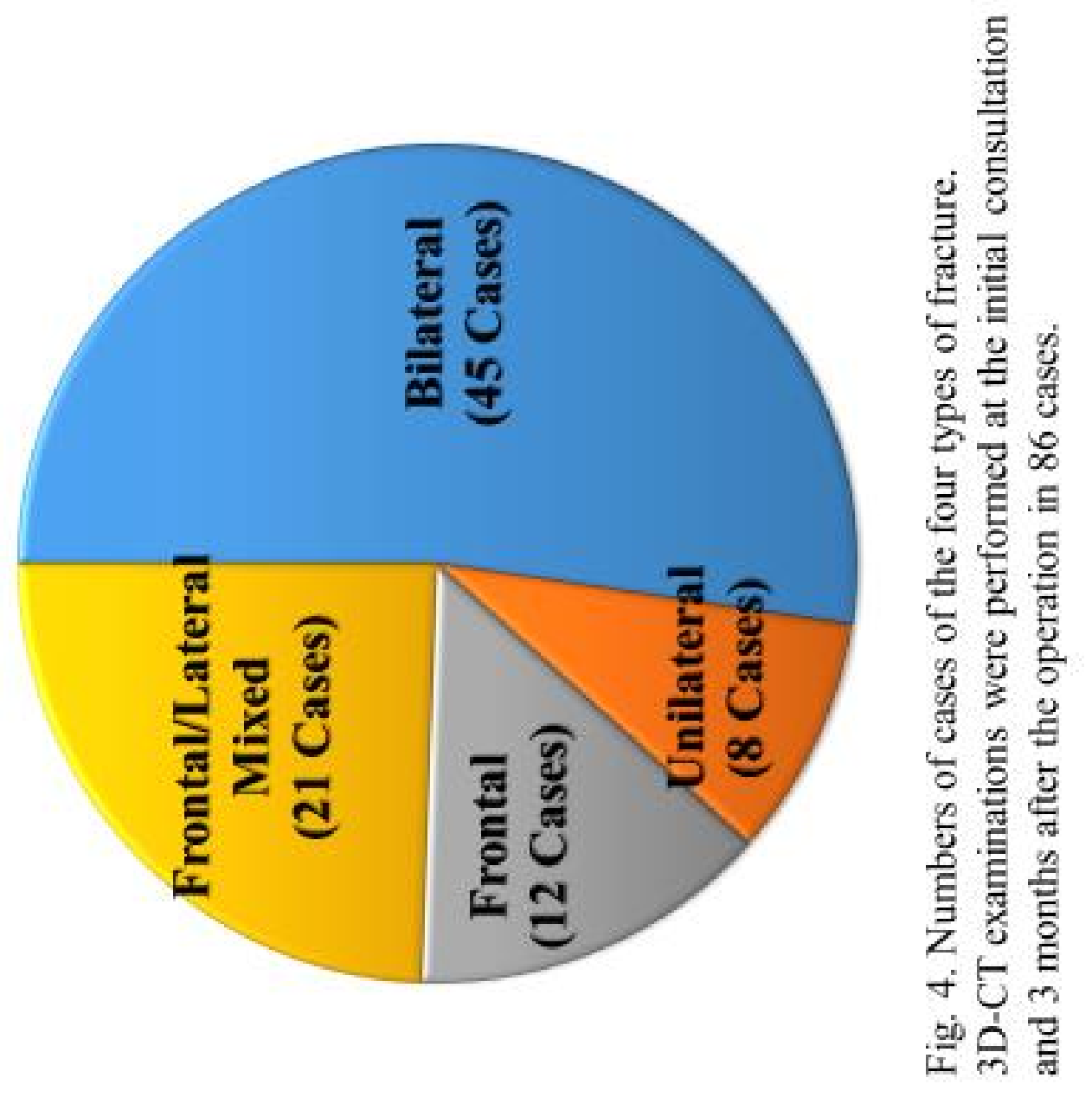




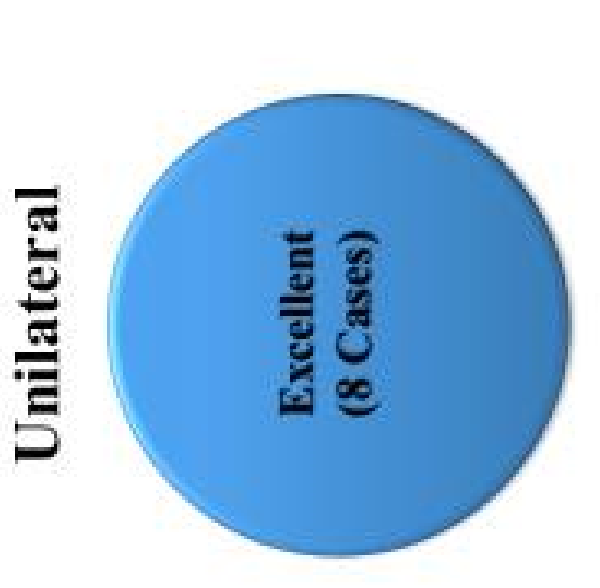

를
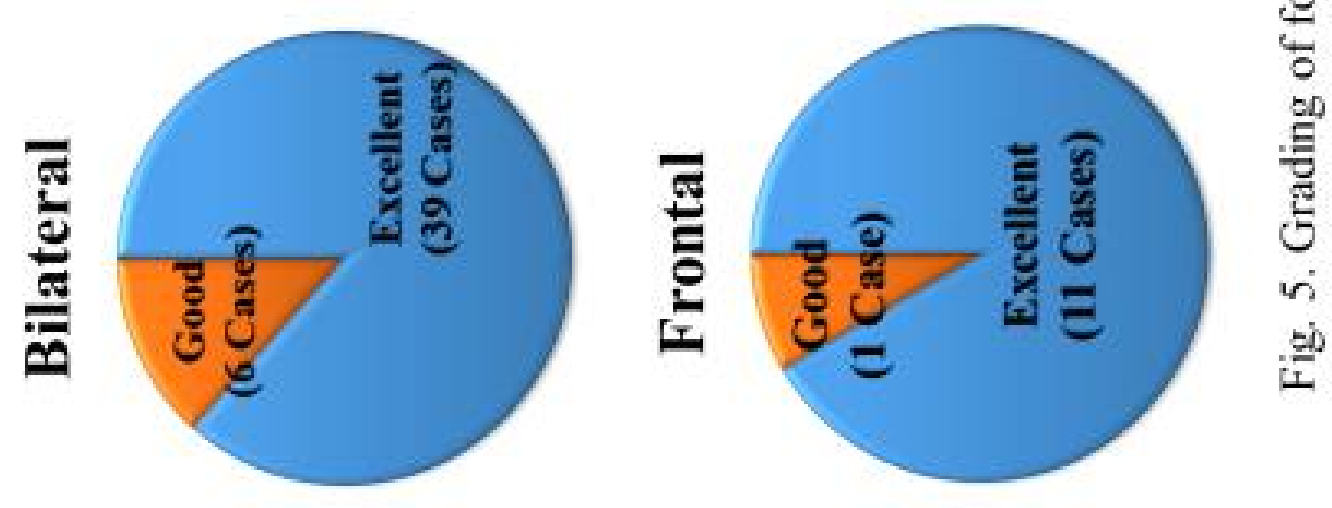


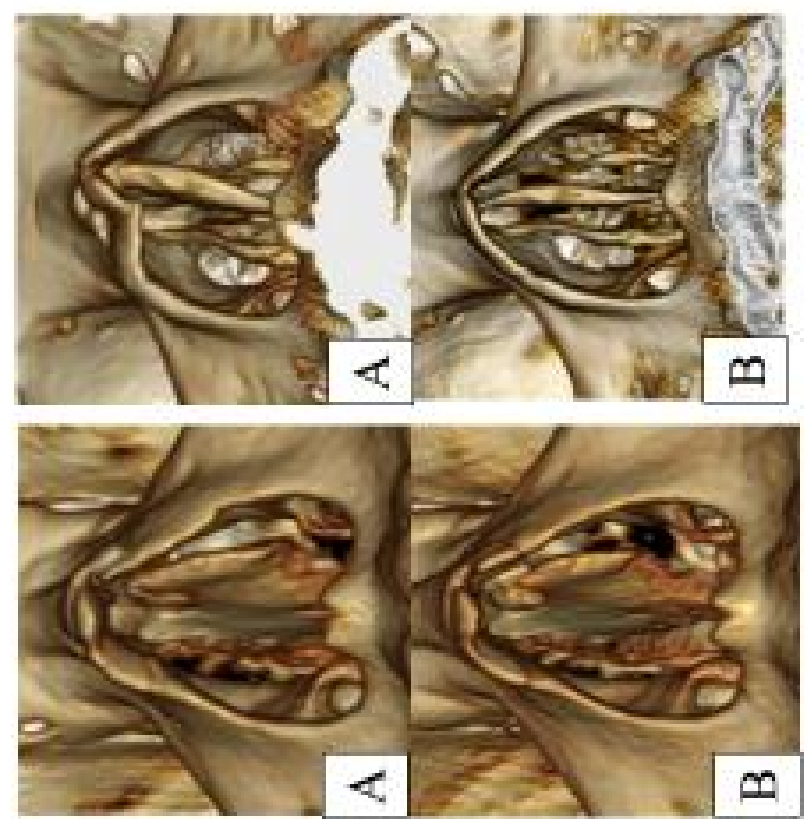

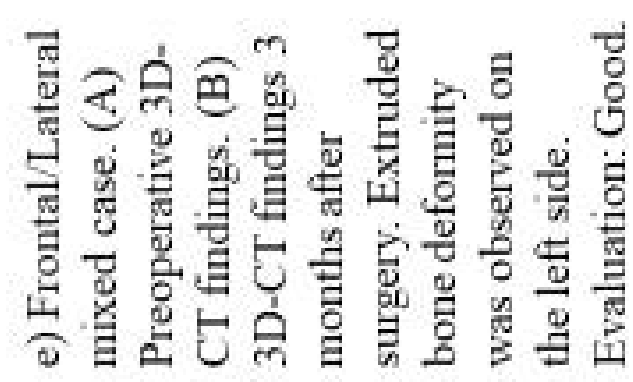

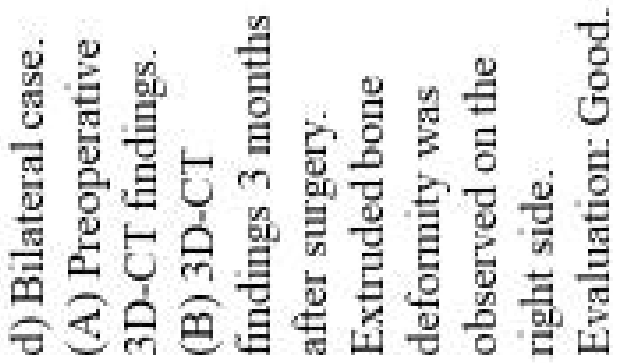

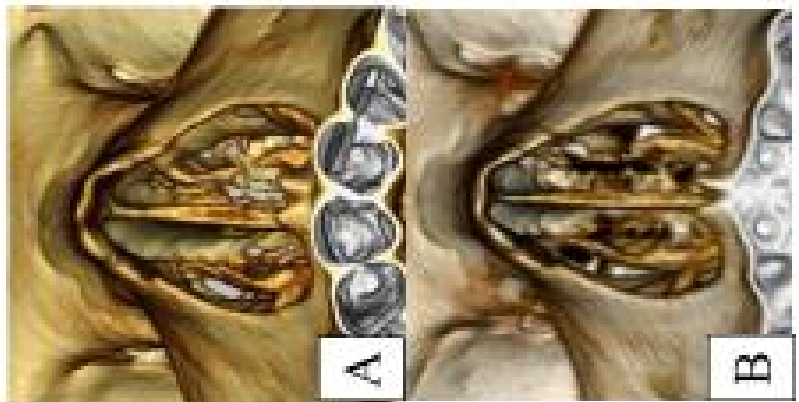

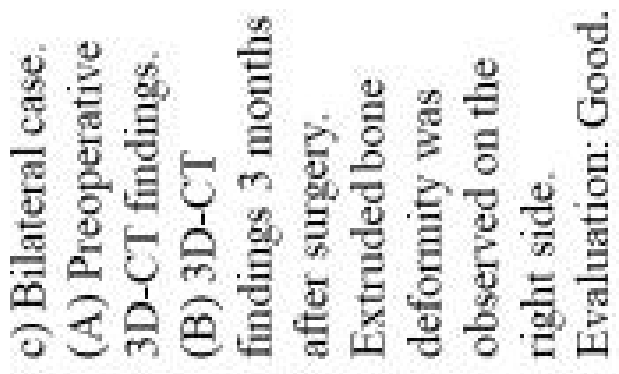

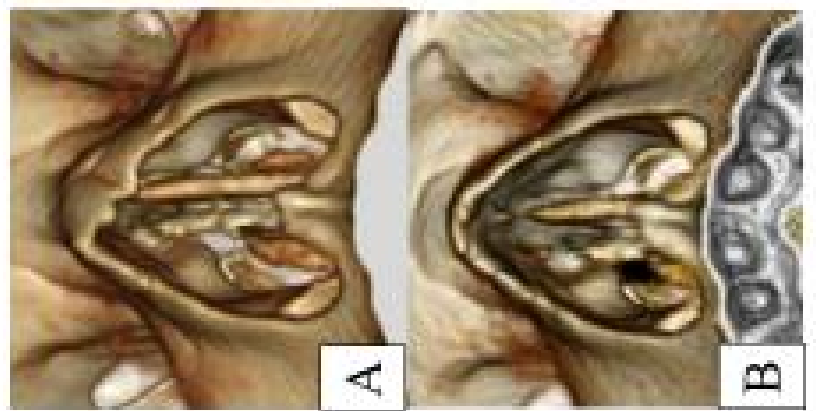

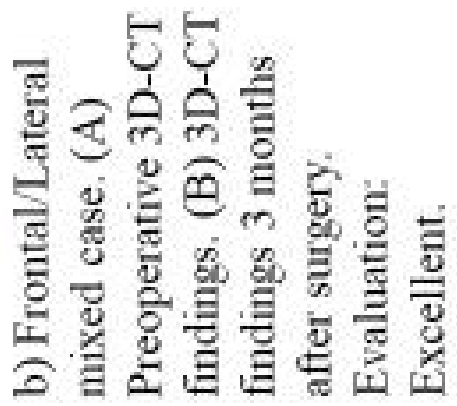

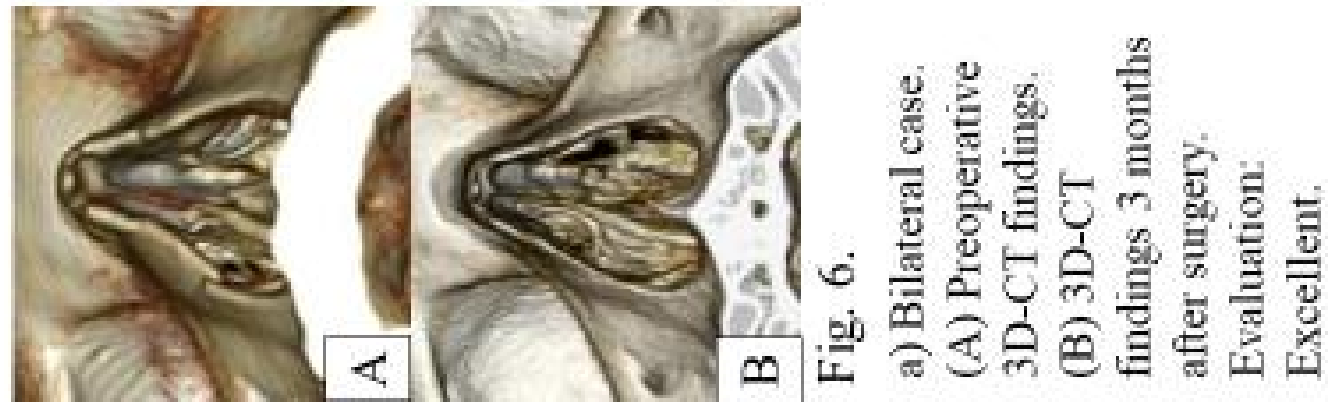




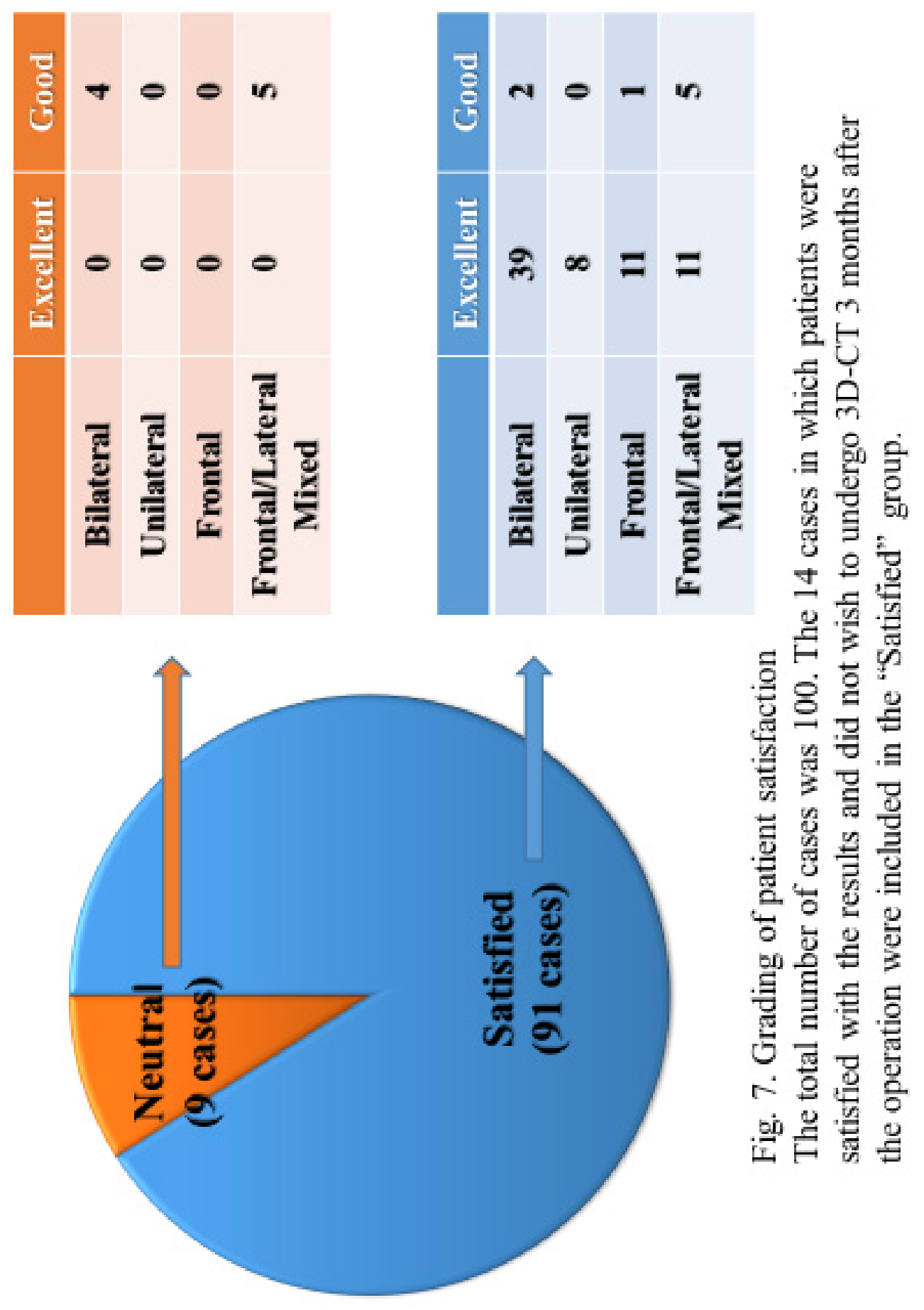

